University of Nebraska - Lincoln

DigitalCommons@University of Nebraska - Lincoln

Educational Psychology Papers and

Publications

Educational Psychology, Department of

January 1992

Consultant and Client Outcomes of Competency-Based

Behavioral Consultation Training

Susan M. Sheridan

University of Nebraska-Lincoln, ssheridan2@unl.edu

Follow this and additional works at: https://digitalcommons.unl.edu/edpsychpapers

Part of the Educational Psychology Commons

Sheridan, Susan M., "Consultant and Client Outcomes of Competency-Based Behavioral Consultation Training" (1992). Educational Psychology Papers and Publications. 67.

https://digitalcommons.unl.edu/edpsychpapers/67

This Article is brought to you for free and open access by the Educational Psychology, Department of at DigitalCommons@University of Nebraska - Lincoln. It has been accepted for inclusion in Educational Psychology Papers and Publications by an authorized administrator of DigitalCommons@University of Nebraska - Lincoln. 
Published in School Psychology Quarterly, 7:4 (1992), pp. 245-270.

Copyright (C) 1992 American Psychological Association. Used by permission. "This article may not exactly replicate the final version published in the APA journal. It is not the copy of record." http://www.apa.org/journals/spq/

This research was funded through a research grant awarded to the author by the University of Utah Research Committee. Special acknowledgements go to Candace Cartwright Dee, Susan Dickinson, Connie Dilts, JoAnn Galloway, and Pam Plant for serving as consultants in the study. Gratitude is also extended to Julie Bowen and Denise Colton for their assistance as research aides.

\title{
Consultant and Client Outcomes of Competency-Based Behavioral Consultation Training
}

\author{
Susan M. Sheridan \\ University of Utah
}

\begin{abstract}
This article examines how despite increasing demands and empirical support for consultation, its actual practice in schools continues to be limited. One barrier to the systematic provision of consultation services in the schools may be the lack of applied training provided to preservice individuals in graduate preparation programs. A model of behavioral consultation training which extends previous competency-based programs is presented. Trained five doctoral students in school psychology in behavioral consultation procedures using written manuals, videotape models, behavioral rehearsal, performance feedback, self-monitoring, and generalization training. Following university-based practice with trained consultees and student teachers, consultants were assigned consultation cases with teachers who presented actual cases. Direct observations of consultant skills and client outcomes are presented, as well as consumer satisfaction and consultation acceptability as rated by student teachers and teacher consultees.
\end{abstract}

Demands for increasing the amount of consultation services in schools are evident from various sources. There are growing numbers of students requiring alternative assistance (Saxe, Cross, \& Silverman, 1988), however current models of service delivery appear to be ineffective in meeting the needs of these children and adolescents (Christenson, Ysseldyke, \& Algozzine, 1982; Knitzer, 1982; Ysseldyke, Algozzine, Richey, \& Graden, 1982). Individuals across disciplines have advocated for alternative methods of addressing the needs of all students (AASA, 1988; Lloyd, Singh, \& Repp, 1991; NASP/NCAS, 1985; Phillips \& McCullough, 1990; Stainback \& Stainback, 1991; Zins, Curtis, Graden, \& Ponti, 1988 ) and consultation has been offered as the foundation for a range of alter- 
native services designed to enhance general educational experiences (Curtis \& Meyers, 1988; Sheridan \& Kratochwill, 1991).

Reviews of the empirical literature have suggested that consultation is an effective model of educational service delivery (Mannino \& Shore, 1975; Medway, 1979; Medway \& Updyke, 1985). Among the various models of consultation, the behavioral approach has received the most research attention (Alpert \& Yammer, 1983) and empirical support (Medway \& Updyke, 1985). For purposes of this article, behavioral consultation is defined as a systematic, indirect form of service-delivery in which two or more persons work together to identify, analyze, remediate, and evaluate a client's needs. Compared to other forms of consultation, behavioral consultation is characterized by (a) the use of a standard four-stage problem-solving process, (b) adherence to behavioral assessment techniques, (c) reliance on behavioral intervention strategies, and (d) evaluation of outcomes based on behavioral analysis and related methodologies. Although methodological problems have been noted in regard to consultation research (Gresham \& Kendall, 1987), several recent experimental studies have illustrated the effectiveness of behavioral consultation in effecting client change (e.g., Fuchs, Fuchs, \& Bahr, 1990; Pray, Kramer, \& Lindskog, 1986; Sheridan, Kratochwill, \& Elliott, 1990).

The process of behavioral consultation (BC) is presented in four stages including problem identification, problem analysis, treatment implementation, and treatment evaluation (Bergan \& Kratochwill, 1990; Kratochwill \& Bergan, 1990). With the exception of the treatment implementation phase, the stages of $\mathrm{BC}$ are procedurally operationalized through three interviews. The problem identification interview involves specifying the problems to be targeted in consultation. Problem analysis focuses on exploration of the problem through the evaluation of baseline data, identification of variables that might facilitate a solution to the problem, and development of a specific plan to implement during the treatment phase. Treatment implementation involves the introduction of a plan that is designed during problem analysis. Finally, treatment evaluation is undertaken in a formal interview to determine the extent to which the intervention plan is successful.

Despite increased demands and empirical support, consultation practice in schools continues to be limited (Curtis \& Meyers, 1988; West \& Idol, 1987). This may be due in part to limited time, lack of administrative support (IdolMaestas \& Ritter, 1985), competing job demands, or lack of training (Curtis \& Meyers, 1988). Although consultation coursework is now included in many preservice programs, few prospective school psychologists receive supervised experience in consultation. There is a recognized need in preservice training programs to prepare students formally and actively in the principles and procedures of school-based consultation.

Training in consultation is important for several reasons. First, as a means of delivering functional services, consultation can provide a direct link between assessment and treatment (Sheridan \& Elliott, 1991). Second, training represents 
the foundation for conducting consultation with integrity and addressing standards for practice (Kratochwill, Sheridan, Rotto, \& Salmon, 1992). Competencybased training represents the basis for providing high quality consultation services and ensuring important standards for practice.

\section{COMPETENCY-BASED BEHAVIORAL CONSULTATION TRAINING}

In competency-based behavioral consultation training models, trainees are exposed to a number of standardized materials and procedures to facilitate the learning of discrete consultation skills. The standard competency-based BC training package includes a procedural manual (Kratochwill \& Bergan, 1990), a videotaped model of a school psychologist consultant and classroom teacher completing $\mathrm{BC}$ interviews, behavioral rehearsal with a trained consultee, consultant self-monitoring of behavioral objectives, and performance feedback by a skilled supervisor. Consultant-trainees complete these procedures and continue to engage in role-playing, self-monitoring, and individualized supervision until they demonstrate attainment ("mastery") of the BC interview objectives.

Behavioral objectives for the problem identification, problem analysis, and treatment evaluation interviews accompany the training manual. The objectives consist of required verbal behaviors to be elicited by the consultant for successful completion of each interview. Specific objectives of each interview are presented in Table 1. These specific objectives were identified to maximize a consultant's success at identifying, analyzing, and evaluating a problem and its associated intervention. The use of standardized, competency-based materials is desirable because they provide a scripted format for novice interviewers, enhance consultation integrity, and ensure attainment of the goals and objectives of behavioral consultation.

One of the most well-developed competency-based BC training programs was originally described by Kratochwill and Bergan (1978). This program has been evaluated in recent years. In an extensive three-part investigation, Kratochwill, Van Someren, and Sheridan (1989) used variations of the standard competency-based $\mathrm{BC}$ program to train school psychology graduate students to conduct consultation interviews in analogue settings (i.e., interviews were conducted on hypothetical cases in a psychoeducational clinic). Practicing school psychologists also were trained to use the procedures with actual consultees. The results of each investigation indicated that the training package was effective and costefficient at training BC interview skills. Furthermore, the authors found that the percentage of criterion objectives met was equivalent to or higher for subjects using the procedures in natural settings. However, only two subjects used the skills in actual cases, and these individuals were experienced school psychology practitioners. Thus, although they had not had previous consultation training prior to their involvement in this study, it is possible that the demonstration of consultation skills was a function of their extensive experience in school settings, and not related directly to specific training. 
Table 1. Stages and Objectives in Behavioral Consultation

I. Problem Identification

A. Define the problem(s) in behavioral terms.

B. Provide a tentative identification of antecedent, situation, and consequent conditions.

C. Provide a tentative strength of the behavior (e.g., frequency or severity).

D. Establish a procedure for collection of baseline data including sampling plan, and what, how and by whom it is to be recorded.

II. Problem Analysis

A. Evaluate and obtain agreement on the sufficiency and adequacy of baseline data.

B. Conduct a tentative functional analysis (i.e., discuss antecedent, consequent, and sequential conditions).

C. Discuss and reach agreement on a goal for behavior change.

D. Design an intervention plan including specification of conditions to be changed and the practical guidelines regarding treatment implementation.

E. Reaffirm record-keeping procedures.

III. Treatment Implementation

A. Determine whether the consultee has the necessary skills to implement the plan effectively.

B. Monitor the data collection procedures and determine whether the plan is proceeding as designed.

C. Determine whether any early changes or revisions in the treatment plan are necessary.

IV. Treatment Evaluation

A. Determine whether the goals of consultation have been obtained.

B. Evaluate the effectiveness of the treatment plan.

C. Discuss strategies and tactics regarding the continuation, modification, or termination of the treatment plan.

D. Schedule additional interviews if necessary, or terminate consultation.

Note. From Sheridan, S. M. and Kratochwill, T. R. (1991). Behavioral consultation in educational settings. In J. W. Lloyd, N. N. Singh, and A. C. Repp (Eds.), The Regular Education Initiative: Alternative perspectives on concepts, issues, and models (pp. 193-210). Sycamore, IL: Sycamore Publishing Co.

Kratochwill, Sheridan, Rotto, and Salmon (1991) extended earlier work in this area in a three-part training project. A total of 15 consultant trainees completed the program. In Experiment 1, five consultants were exposed to a training package consisting of a manual, videotaped models, behavioral rehearsal, and performance feedback. Following training, all consultant subjects completed actual cases with teachers of behaviorally/emotionally disordered students. Experiment 2 utilized identical standardized procedures with some modifications. Specifically, readings and workshops on interpersonal skills and entry/systems issues were integrated into training. Experiment 3 was a further extension, with one consultant receiving mentor training. ${ }^{1}$ Results of all three experiments indicated that the training package and its variations were effective in teaching consulta-

1. Detailed descriptions of the standardized competency-based behavioral consultation training program are beyond the scope of this article. Interested readers are referred to Kratochwill, Sheridan, Rotto, and Salmon (1991) and Sheridan, Salmon, Kratochwill, and Rotto (1992). 
tion skills to novice consultants. However, although consultants were assigned to work with teachers on actual school cases, no child-related outcome data were reported. Likewise, although student teachers were involved as consultees in a transition stage of training, no data were collected on the impact of services on these individuals. Finally, although data were reported on teachers' perceptions of consultants' skills, this and previous studies failed to assess consultation acceptability (i.e., the degree to which consultees find $\mathrm{BC}$ an acceptable method of service delivery).

The purpose of the present study was to extend the research by Kratochwill and his colleagues. Training manuals, videotaped models, and client scripts were used to introduce consultation objectives to school psychology student trainees. Student teachers were included in training to promote generalization of consultant skills from hypothetical to actual cases, and data were collected on their perceptions of the model. All consultants completed actual cases following university-based training and student teacher interviews. Systematic self-evaluation and individualized feedback were used to broaden subjects' conceptualization of consultation cases. Data on client outcomes, consumer satisfaction, and consultation acceptability were collected for actual field-based consultation cases.

\section{Objectives and Research Questions}

The specific objectives of the study were to: (a) train five school psychology graduate students in the principles and procedures of behavioral consultation, including the areas of interpersonal skills and relationship variables, (b) generalize the newly learned consultation skills to naturalistic school settings, (c) assess effectiveness of consultation on an individual child outcome level, (d) evaluate teachers' ratings of consultation acceptability based on their interactions with the student consultant in actual casework, and (e) examine trainees' perceptions of the consultation training program.

\section{METHODS}

The training program was implemented in three broad phases. Phase 1 involved the initial training of behavioral consultants, wherein consultant subjects engaged in analogue role-plays with trained consultees who presented behavioral data on a hypothetical child. Phase 2 was a transition phase, which involved pairing consultants with student teachers who presented behavioral information on an actual student. During Phase 3, trained consultants worked with inservice teachers on actual consultation cases in elementary schools.

\section{Subjects}

Consultants. Five graduate students in a school psychology training program participated as consultants. All subjects were female, ranging in age from 36 to 
44. All consultants were enrolled in a school psychology doctoral program. All but one had earned a Master's degree in school psychology or a related field. Two were in their second year of school psychology training, two were in their third year, and one was more advanced. Each provided written consent and was paid $\$ 200$ for participation. All subjects were naive regarding the research design and hypotheses. None of the subjects had received previous training in behavioral consultation skills.

Consultees. Five student teachers, five experienced elementary teachers in local school districts, and two parents served as consultees in the study. All consultees provided written, informed consent to participate. None of the consultees had prior involvement with the student consultants or specific training in behavioral consultation. All teacher consultees were female. Student teachers ranged in age from 19 to 25 , and were completing their first year of student teaching. Inservice teacher consultees ranged in age from 33 to 52 . Their teaching experience ranged from 10 to 18 years. One teacher taught in a preschool handicapped classroom; the remainder taught in regular public elementary classrooms (ranging from kindergarten through grade 6). The parents of a preschool handicapped child participated in consultation with the consultant and their child's teacher to pilot a parent-teacher behavioral consultation model.

Child Clients. Five child subjects (one girl and four boys) served as consultation clients in the study. The child subjects were chosen by teachers based on difficulties that they had been exhibiting in the classroom. Parents of each of the students provided consent for their involvement. Child subjects were enrolled in preschool through grade six and their ages ranged from 5 to 11 (mean age $=8$ ). Specific difficulties displayed by the child subjects included off-task behaviors, noise making, noncompliance, social withdrawal, and academic underachievement.

\section{Setting}

All baseline and analogue training phases were conducted in a research suite at a large western university. School-based consultation cases were conducted in five elementary schools from three districts (one urban and two suburban). All case interviews were conducted in the classrooms of respective teachers.

\section{Behavioral Consultation Training Procedures}

A multimethod training technology (i.e., manuals, videotaped models, simulated role-play situations, behavioral rehearsal, self-monitoring, and performance feedback) was used in the project to facilitate the didactic and experiential instruction of BC skills. Specifically, following baseline interviews consultant subjects were given a training package consisting of a standardized $\mathrm{BC}$ training manual (Kratochwill \& Bergan, 1990), an interpersonal skills training manual (Rotto, Sheridan, \& Salmon, 1987), and a videotape model of a consultant and a teacher completing three BC interviews. Self-monitoring and direct supervision with the investigator supplemented training. 


\section{Table 2. Training Components and Procedures}

I. Procedural and Interpersonal Skills (Approximately 3 weeks)

A. Behavioral consultation procedural manual (Week 1)

1. Read entire training manual (i.e., Kratochwill \& Bergan, 1990)

2. Complete self-quizzes

B. Interpersonal/Relationship skills manual (Week 2)

1. Read entire manual (i.e., Rotto et al., 1987)

2. Complete self-report exercises

3. Discuss in small groups (optional)

4. Complete discussion questions in small groups (optional)

C. Behavioral consultation videotape (Week 2)

1. View in small groups

2. Stop tape and discuss consultant performance

3. Complete process sheets (identify specific strengths, weaknesses, and overall impressions)

D. Analogue role-plays (Weeks 2 and 3)

1. Conduct two role-plays of entire $\mathrm{BC}$ interview process

2. Audiotape all interviews

3. Self-monitor performance on objectives checklist

4. Complete consultation log; establish procedural goals

5. Receive supervision following each role-play

E. Library/training modules (On-going)

1. Include behavioral consultation references

2. Include references on child, population, and family characteristics

3. Include references on behavioral assessment, analysis, and evaluation

II. Transition Interviews (Week 4)

A. Conduct role-play of entire $\mathrm{BC}$ interview process with student teacher

B. Audiotape all interviews

C. Self-monitor performance on objectives checklist

D. Complete consultation log; establish procedural, interpersonal, and context-related goals

E. Receive supervision

F. Receive verbal feedback from teacher consultee

III. Field-Based Experience (Approximately 3 months)

A. Consultation case

1. Complete entire $\mathrm{BC}$ process with teacher

2. Audiotape and listen to all interviews

3. Self-monitor performance on objectives checklist

4. Reflect on performance and complete consultation log

5. Establish procedural, interpersonal, and context-related goals for subsequent interviews based on performance in previous interview and supervision

B. Supervision

1. Receive supervision following each interview

2. Reconsider problem situations with supervisor in a systematic fashion

3. Review logs and determine adequacy of goals

4. Re-establish procedural and interpersonal goals for subsequent interview, if necessary

5. Meet with other consultant-trainees to share experiences and gain different perspectives 
A summary of the training components is presented in Table 2. Subjects were allowed an average of 10 days to complete the training materials and conduct their first interview. The total time required for individuals to complete training (including readings, videotape, role-plays and supervision) was approximately 20 hours.

Behavioral Consultation Individual Guide. The primary training component was a behavioral consultation manual (Kratochwill \& Bergan, 1990). It is designed to assist mental health professionals in developing behavioral consultation skills by presenting a standardized interview format to accompany each stage of problem-solving. For each stage of BC, the guide presents objectives, procedural guidelines, specific interview tactics, and a structured interview format. Selfquizzes are also included to provide an opportunity to evaluate cognitive understanding of the concepts presented.

Interpersonal Skills Manual. Along with procedural and discrete verbalization skills, basic interpersonal and communication skills are essential at every stage of consultation. However, the literature on integration of affective and cooperative relationship skills into BC is extremely limited (Sheridan, Salmon, Kratochwill, \& Rotto, 1992). In the present study, consultants were assigned a manual (Rotto et al., 1987) to provide a systematic framework for training interpersonal skills within the context of behavioral consultation.

Videotape Model. In addition to the training manuals, subjects were exposed to a videotape model of the $\mathrm{BC}$ process. The consultant in the tape was a female advanced school psychology graduate student previously trained in behavioral consultation. The consultee, also a female, was an experienced teacher of severely behaviorally disordered children. The entire videotape, including all three $\mathrm{BC}$ interviews, was approximately 90 minutes in length.

Role-Plays and Client Problem Scripts. After completing each of the aforementioned training components (i.e., review of two manuals, completion of selfquizzes, and viewing of the videotape), consultants engaged in analogue roleplays with trained "consultees." Specifically, three trained consultees role-played the part of a teacher who presented information on a target child. Each trained consultee was responsible for learning three of nine problem scripts (see Kratochwill et al., 1991). After studying the scripts, the consultees were tested by the experimenter to ensure that they could recite the problem scripts verbatim. Likewise, all sessions with the consultants were audiotaped to monitor the integrity of consultee responses, and allow for consultee feedback and instruction.

Self-Monitoring. Subjects reviewed their own consultation interview sessions and self-monitored their own performance in several domains. Specifically, subjects coded their own interviews on a BC criterion objectives checklist (Kratochwill \& Bergan, 1990) and completed a scale of consultant interpersonal skills. Likewise, they completed consultation logs (Wilson, Curtis, \& Zins, 1987) to help identify subjective feelings experienced during interviews, determine performance strengths and weaknesses, and develop personal goals for future consultation interviews. 
Consultation Supervision/Performance Feedback. The audiotapes and selfevaluation forms were used in supervision sessions with the experimenter. Specifically, the investigator listened to the audiotapes and provided feedback on (a) adherence to the $\mathrm{BC}$ model; (b) interpersonal and communication skills; and (c) appropriateness of self-generated goals for future consultation interviews. This format for supervision was used throughout all phases of the study.

\section{Dependent Variables}

Several direct and indirect measures comprised the dependent measures in the study. Outcome data on consultant skills, client behaviors, consumer satisfaction, and consultation acceptability were collected.

Consultant Skills. A number of criterion objectives have been identified for each BC interview (Kratochwill \& Bergan, 1990). The objectives consist of required verbal behaviors to be elicited or emitted by the consultant for successful completion of each interview. The Problem Identification (PII), Problem Analysis (PAI), and Treatment Evaluation Interviews (TEI) include 22, 13, and 12 objectives, respectively. Each consultant must meet a criterion of at least $80 \%$ for each interview during each training phase.

Attainment of criterion objectives was determined from audiotapes by trained raters. Three graduate students in educational psychology completed training, which included (a) a written overview of the goals and objectives of BC (Kratochwill \& Bergan, 1990); (b) definitions of specific objectives for each BC interview (see Kratochwill, Elliott, \& Rotto, 1990); (c) two training workshops; (d) practice scripts; and (e) practice audiotapes. Across training sessions, percentages of interobserver agreement were $94 \%$ for PIIs, $94 \%$ for PAIs, and $92 \%$ for TEIs.

Forty-four percent (44\%) of the interview sessions were coded by two raters. Approximately equal percentages of reliability ratings were obtained across all subjects, types of interviews (i.e., PII, PAI, TEI), and phases of the study (baseline, post-training, student teacher interviews, and school cases). Across all interviews, agreement rates between coders ranged from $67 \%-100 \%$, with an average agreement of $88 \%$. Average agreement percentages for PIIs, PAIs, and TEIs were $89 \%, 90 \%$, and $86 \%$, respectively. Kappa coefficients of .70, .78, and .62, were yielded for PIIs, PAIs, and TEIs, respectively. Current guidelines suggest that acceptable levels of reliability fall in the .70 to .90 range for percentage agreement, and .60 to .75 for Kappa statistics (Gelfand \& Hartmann, 1984).

Child Behaviors. Observational data were collected for each child subject targeted in school cases. For the majority of cases, data were collected by teachers on a daily basis, and by independent classroom observers approximately once per week. Independent observers were blind regarding case hypotheses, stage of consultation, and specific details and status of intervention procedures.

Subject 1 ("Peter") was an 8-year-old second grade boy who was referred for consultation due to atypical social behaviors which appeared to alienate him from his peers. The most frequent complaints about Peter from his peers were his "noise-making" behaviors, so these were targeted for intervention. Noise mak- 
ing was operationally defined as emitting a discriminative sound from the mouth at a level that was above the normal tone of the classroom, that was not a word or meaningful attempt to communicate a message to another, and that could be heard by others not directly next to Peter.

Subject 2 ("Tommy") was a 5-year-old kindergarten student, who was referred for consultation due to poor attending skills, difficulty initiating and completing assignments, difficulty understanding instructions, poor academic skills, and an inability to ask for help when needed. In order to focus behavioral consultation efforts, beginning and completing work were identified as priority behaviors. These were operationally defined as receiving instruction, proceeding to work area, beginning work within 5 minutes without any interfering behaviors (e.g., playing with crayons, tote, pencils), and completing all items or requirements of the assigned task. Tommy's teacher agreed to conduct a behavioral observation 5 minutes after instructions were given to monitor the target behavior of "beginning work."

Subject 3 ("David") was an 11-year-old sixth grade student who was referred for consultation due to withdrawal from class activities and low level of classroom participation. Classroom participation was operationally defined as volunteering information, asking a question, or answering a question asked by the teacher or other individual.

Subject 4 ("Laura") was a 5-year-old preschool child enrolled in a preschool handicapped program. Laura was diagnosed as having cerebral palsy at one year of age. Motor and language development were delayed, however Laura's cognitive abilities were estimated to be within the average range. A conjoint behavioral consultation approach (Sheridan \& Kratochwill, 1992; Sheridan et al., 1990) was instituted in Laura's case, which involved her teacher and parents serving as joint consultees (i.e., all of the interviews were conducted with her teacher and parents together). The primary referral concern expressed by both Laura's teacher and parents was her inconsistent responding to questions asked of her, which included a tendency toward silence and difficulties initiating and maintaining conversations. Thus, responding to questions was the behavior chosen for intervention.

Subject 5 ("Jason") was a 10 year-old fifth grade student. He was referred for consultation due to a number of inappropriate behaviors, including arguing with the teacher, tattling on classmates, failing to follow rules, lack of cooperation with peers, and disorganized, off-task behaviors. Jason had a history of difficulties in school. He had been evaluated for special education previously, but he was determined ineligible. Given various complexities of the case, difficulties ensued in selecting an appropriate target, collecting accurate data, and implementing a behavioral intervention. Compliance to directives was initially targeted in consultation, however certain classroom and situational conditions contributed to on-going difficulties in obtaining consistent behavioral data. The teacher also reported problems in providing systematic contingencies for Jason's behaviors as specified in various intervention plans. The final behavior targeted was Jason's 
excessive questioning, defined as asking insignificant questions regarding work that had already been explained to the group, or questions regarding upcoming class activities that were not relevant at the time.

The Behavioral Observation Manual (Rotto \& Sheridan, 1987) was used to train two graduate students in methods for conducting behavioral observations (i.e., event, partial and whole interval, time sampling, latency, and duration methods). The manual is equipped with standard forms that can be used in various settings. Observers were trained in a series of workshops which involved reviewing the definitions and procedures of each observational technique, viewing of videotapes of children in classroom and playground settings, and conducting observations of target behaviors. During training, observers demonstrated $96 \%$ agreement, with a kappa coefficient of 87 .

Consultation Acceptability. The Behavior Intervention Rating Scale (BIRS; Von Brock \& Elliott, 1987) is a 24-item Likert scale which was designed to assess consultees' acceptability of various behavioral interventions. Possible item responses on the BIRS range from 1 (low acceptability) to 6 (high acceptability). Reliability of the BIRS has been established, with an internal reliability alpha coefficient of .97. Oblique factor analyses have identified three primary factors on the BIRS: Acceptability, Effectiveness, and Time. Together, these factors account for $73.6 \%$ of the total variance. Pearson coefficients computed between the Acceptability and Effectiveness scales, the Acceptability and Time scales, and the Effectiveness and Time scales resulted in correlations of .79, .65, and .63, respectively. These results suggest that the BIRS is comprised of three distinct factors which can be assessed reliably (Elliott \& Von Brock Treuting, 1991; Von Brock \& Elliott, 1987). In the present study, the BIRS was revised to assess acceptability of the consultation services provided.

Consumer Satisfaction. Following completion of the consultation cases, consultant and consultee subjects were asked to complete consumer satisfaction measures. Consultants completed the Training Satisfaction Questionnaire (TSQ), a 21-item Likert scale developed for this study, which measures satisfaction with general training procedures and specific training components. Part 1 of the TSQ contains eight items assessing general satisfaction with training (e.g., "Did you receive the kind of consultation training you wanted?"; "To what extent has the consultation training program met your needs?"). Possible responses range from 1 (low) to 4 (high), with a total possible score of 32. Part 2 of the TSQ contains ten items pertaining to the degree of helpfulness of specific training components (e.g., behavioral consultation guide; individual supervision). These are rated on a 5-point Likert scale ( $1=$ not at all helpful; $5=$ extremely helpful). Part 3 consists of two open-ended questions regarding perceived strengths and weaknesses of the training program.

The Consultation Services Questionnaire (CSQ; Zins, 1981) was used to assess consultees satisfaction with consultation services. The CSQ is a 26-item scale comprised of three sections. Part 1 of the scale contains 17 items assessing general perceptions of the consultant. Part 2 consists of 5 items assessing con- 
sultees' perceptions of benefits gleaned from working with the consultant. Four additional items are included in Part 3 to measure satisfaction with strategies developed, success of strategies, confidence in abilities to solve similar problems in the future, and overall effectiveness of the consultant. All CSQ items are rated on a scale of 1 (low) to 5 (high). The CSQ has provided useful consumer self-report data in previous consultation research (Kratochwill et al., 1991; Zins, 1984), although its psychometric properties have not been determined to date.

\section{Experimental Design and Procedure}

A combined series multiple baseline design across subjects (consultants) and case study methodologies were used in the study. Consultant subjects were paired for training (i.e., exposed to training materials in groups of two or three) to avoid extended baselines for the last subjects (Barlow, Hayes, \& Nelson, 1984). Following baseline interviews, each consultant subject was exposed to the training package in a staggered fashion. Each subject then completed two sets of roleplay interviews with trained consultees, followed by one series of interviews with a student teacher to aid the transition to actual school cases. Following completion of student-teacher interviews, these consultees completed the BIRS-R and CSQ.

As consultants completed clinic-based training, teachers and child subjects were identified in local school districts. Given the variability of client needs and case considerations, individual case studies were conducted to evaluate outcome for child subjects. Baseline data were collected in all cases; however, because target behaviors were not identical, these data varied across subjects. Systematic behavioral observations by teachers and independent observers were attempted in all cases, but logistical constraints (e.g., absenteeism, teacher resistance, scheduling conflicts) precluded this for some subjects. Behavioral checklists were also collected prior to and following intervention in some cases, depending on consultant preference. Upon completion of each case, teacher consultees completed the BIRS-R and CSQ. At the end of the study, consultants completed the TSQ.

\section{RESULTS}

\section{Consultant Behavior}

Data depicting consultants' demonstration of $\mathrm{BC}$ criterion objectives are presented in Figure 1. Baseline performances across consultants ranged from $23 \%$ to $77 \%$, with an average of $52 \%$. During Phase 1 of training, consultants demonstrated between $59 \%$ and $100 \%$ mastery of criterion objectives, with an average of $87 \%$. In the transition phase with student teachers, consultants met between $76 \%$ and $100 \%$ of interview objectives, with an average of $92 \%$. In the school consultation cases, consultants met between $64 \%$ and $100 \%$ of behavioral consultation objectives, with an average of $88 \%$. 


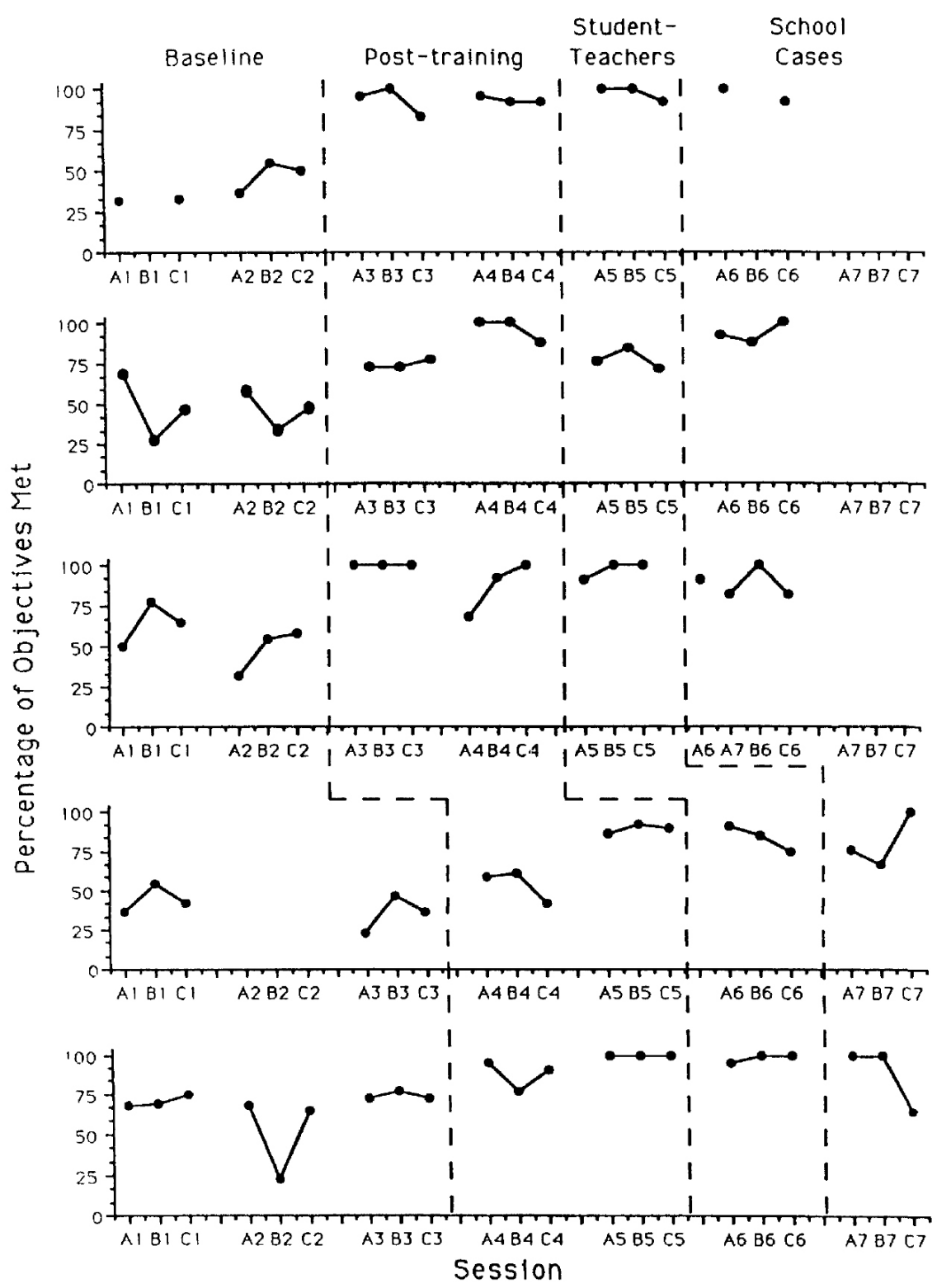

Lete: $A=$ Problem Identification Intervlew; $B=$ Problem Analysis Interview; $\mathrm{C}=$ Treatment Evaluation Interview

Figure 1. Percentage of verbal objectives met across all subjects and phases of training (baseline, post-training, student teachers, school cases). 


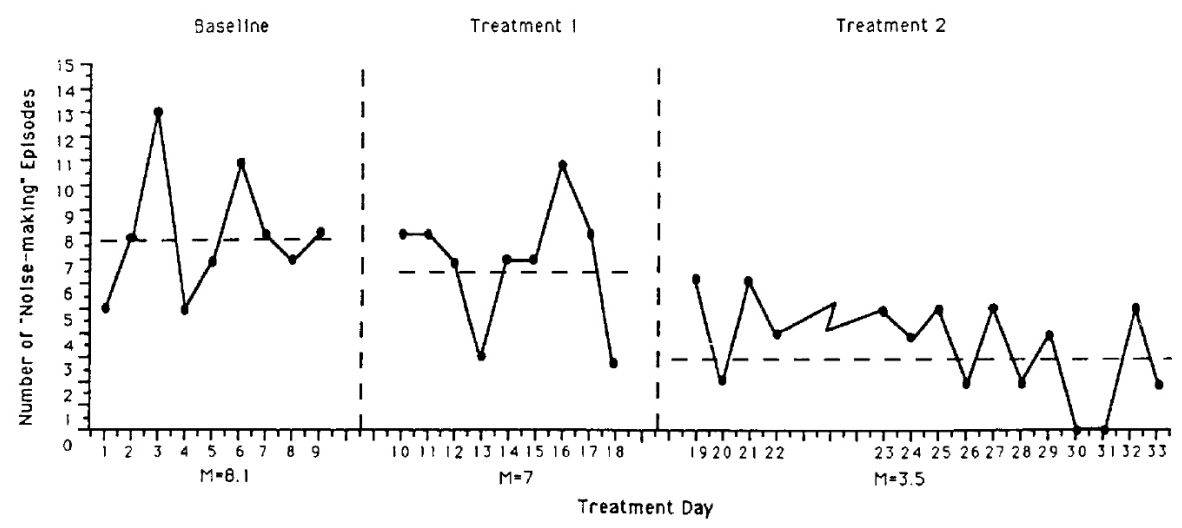

Note: Break Detween days 22 and 23 indicate a scheduled 2-week school recess Horizontal lines indicate means within phases.

Figure 2. Individual client outcome data for Subject 2 ("Peter").

\section{Child Behavior}

Child-subjects' behaviors were observed in naturalistic settings by trained observers (graduate students in educational psychology) and classroom teachers. Unfortunately, due to practical constraints (e.g., scheduling conflicts, teacher preferences), only three of the cases have systematic data across all phases of consultation. Also due to logistical difficulties, interobserver agreement was not assessed.

Subject 1 (Peter). Behavioral data collected across all stages of consultation for Subject 1 are presented in Figure 2. Baseline data collected for 7 days by Peter's teacher indicated that noise-making episodes during the daily data collection period ranged from 5 to 13 , with a mean of 8.1 per day. During the first phase of treatment (home-note with positive reinforcement), a slight decrease was noted in Peter's noise-making (range $=3$ to 11 episodes per day, mean $=$ 7). A treatment modification was instituted, which involved immediate reinforcement (i.e., stickers) which were exchanged for back-up reinforcers later at home. Data collected over this treatment phase indicated that noise making episodes ranged from 0 to 6 , with a mean of 3.5. Near the end of the second phase of treatment, a student teacher was assigned to Peter's class and reported that she was unable to distinguish his noise making above the general tone of the fairly quiet classroom. As a result, and because of the difficulty of continuing to monitor Peter's behavior as the student teacher took increasing control of the class, consultation and data collection were discontinued at that time.

Subject 2 (Tommy). Baseline data collected by Subject 2's teacher indicated 


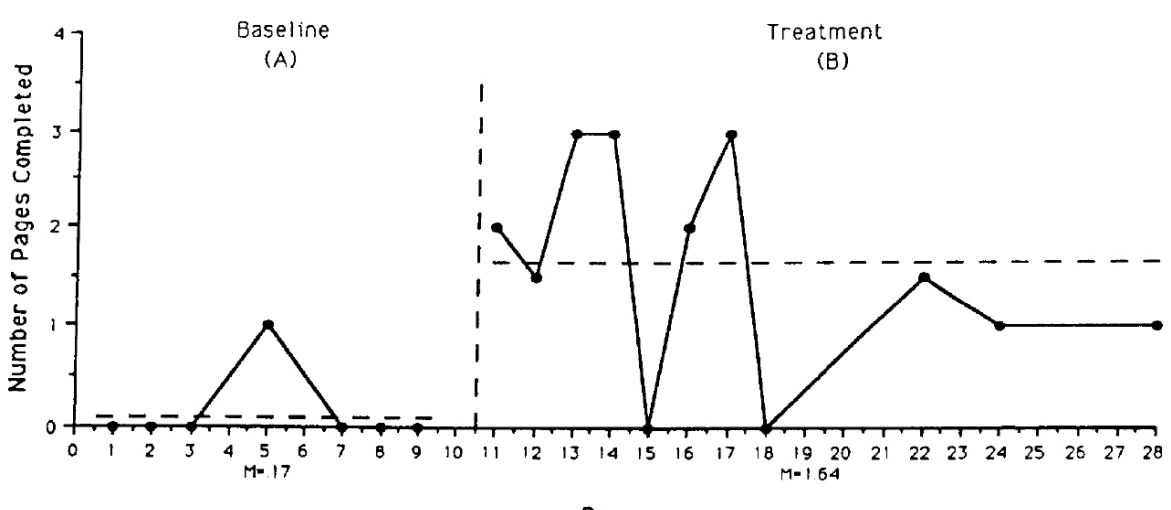

Day

Figure 3. Individual client outcome data for Subject 3 ("Tommy").

that on four of five days, Tommy began working within the first 5 minutes. However, he did not complete all of his assigned work on any day. Out of a total of four pages assigned daily, he completed two sheets one day only. Thus, it appeared that initiation of work was occurring, but the incidence of completion was inappropriately low. The intervention plan involved three components: assignment restructuring (i.e., assign one page at a time), immediate positive reinforcement, and home-based reinforcement. Behavioral data collected on Tommy's work completion are presented in Figure 3. Over the first five days of treatment, Tommy completed at least two pages on at least four days. However, on three of the five days he failed to begin work within the five-minute post-instruction check. Thus, modifications were instituted to incorporate this behavior into the intervention. Unfortunately, Tommy was absent three of the five days during which the modified plan was to be in effect, and end of the school year activities interfered on the days that he was present. Although the intervention was in effect for only a short amount of time, Tommy's mother expressed satisfaction as it provided a form of communication between herself and the school.

Subject 3 (David). Data collected across all phases of consultation with David's teacher are presented in Figure 4. Baseline observations conducted by David's teacher indicated one response on the first day and no responses on three subsequent days. The intervention implemented during consultation consisted of two phases. During Phase I (task restructuring and positive reinforcement), data collected by David's teacher revealed two responses across two days. Treatment Phase II (structured prompting and direct attention) consisted of a volunteer presenting questions to David about an autobiographical scrapbook. During this phase, David demonstrated a significant increase in his amount of participation. Specifically, during the first behavior probe, David answered 19 questions and 


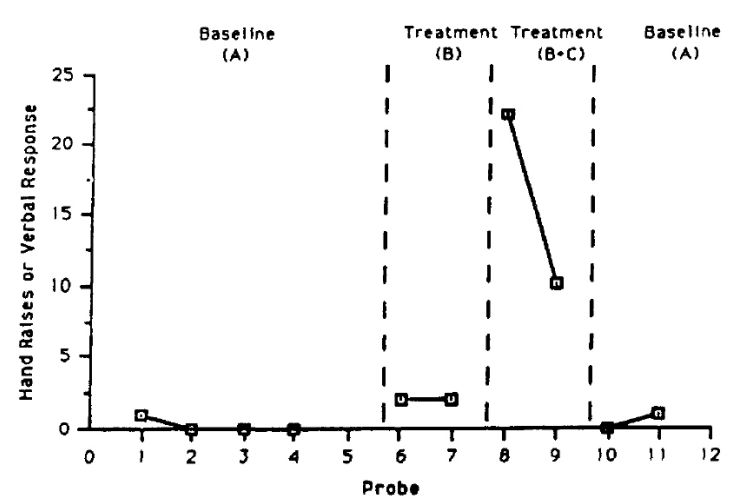

Figure 4. Individual client outcome data for Subject 1 ("David").

posed 3 of his own. During the second probe, he answered 7 questions and posed 3 of his own. Unfortunately, due to the nearing end of the school year, only two days of data were available for Treatment Phase II, and a schedule change necessitated a withdrawal (return to baseline) phase. On the first day of this phase, David made no response. On the second day, however, David approached his teacher spontaneously to show her his successful performance on a spelling test.

Subject 4 (Laura). Parent and teacher rating scales and direct observations were completed as part of Laura's behavioral assessment. On the Social Skills Rating System (SSRS; Gresham \& Elliott, 1990), Laura obtained standard scores of 76 (11th percentile) and 68 (3rd percentile) on the parent and teacher forms, respectively. Baseline data collected by Laura's teacher indicated a great deal of variability in her responding, with an average response rate of $67 \%$. Baseline data collected at home revealed that Laura responded consistently to questions, but responses were often of short duration.

The treatment program developed for Laura to increase her response to questions involved both home and school components. The school program involved modeling, use of visual stimuli to aid verbalization, and positive reinforcement. At home, Laura was positively reinforced for talking, with special trips to her grandmother's house contingent on progress at school. Although only two structured modeling sessions were held at school, Laura responded to an average of $89 \%$ of questions. Due to the limited intervention data, graphic depiction and conclusions regarding Laura's response to treatment are premature. However, teacher ratings on the SSRS revealed a significant increase in Laura's social skills. Specifically, following treatment Laura received a total score of 86, which placed her at the 34th percentile compared to her peers. Unfortunately, post-treatment SSRS data are not available from Laura's parents.

Subject 5 (Jason). In order to limit Jason's excessive questioning, a flow chart 
was developed to allow him to receive answers to his questions without interrupting his teacher. Step 1 in the procedure was to listen to directions. Self-talk was employed at each subsequent step (e.g., "Do I know what to do?"). If further assistance was needed, appropriate steps were outlined (e.g., "ask someone at your table"; "ask someone at another table"). Positive reinforcement and response cost procedures were used to encourage Jason's compliance to the program, which allowed him to earn and lose points for himself and for his group. Unfortunately, the end of the school year made consistent program implementation and data collection difficult. Although exact data are unavailable, Jason's teacher stated that his questioning had decreased, and she expressed that both she and Jason found the intervention acceptable.

\section{Consultation Acceptability}

The Behavioral Intervention Rating Scale-Revised (BIRS-R) was administered to all experienced and student teachers to assess the degree to which they found the consultation procedures acceptable. Because not all teachers responded to each item, mean scores rather than total scores were computed to obtain global ratings of consultee acceptability (i.e., each subject's total score averaged across total number of items to which they responded). Across all inservice teachers, total mean scores ranged from 4.3 to 5.3 (with 1 indicating low acceptability and 6 indicating high acceptability). For student teachers, total mean scores ranged from 4.2 to 5.3. Likewise, individual item scores averaged across all subjects were computed. These data are presented in Table 3. As indicated in the table, the item rated highest by experienced teachers was "the child's behavior problem was severe enough to warrant use of this consultation model." Items rated highest by student teachers included "I would suggest the use of this consultation model to other teachers" and "I would be willing to use this model of consultation in the classroom setting again." The item receiving the lowest ratings for inservice teachers was "this model of consultation produced enough improvement in the child's behavior so the behavior is no longer a problem." For the student teachers, the item receiving the lowest rating was "using this model of consultation not only improved the child's behavior in the classroom, but also in other settings."

\section{Consumer Satisfaction}

Two measures of consumer satisfaction were collected in the study. These included consultant satisfaction with the training program and procedures, and consultee satisfaction with the consultant.

Consultants' Satisfaction with Training. Consultant subjects completed the Training Satisfaction Questionnaire (TSQ) to determine their degree of satisfaction with the consultation training program. Results from this measure indicate that the consultant trainees were very satisfied with training. Because one subject 
Table 3. Item Means on Behavior Intervention Rating Scale—Revised Across Student Teachers and Inservice Teachers

\begin{tabular}{lcccc}
\hline Item & $\begin{array}{c}\text { Student } \\
\text { Teachers }\end{array}$ & Range & $\begin{array}{c}\text { Inservice } \\
\text { Teachers }\end{array}$ & Range \\
\hline 1. Acceptable consultation model & 5.3 & $5-6$ & 5.2 & $5-6$ \\
2. Suitability for other problems & 5.3 & $5-6$ & 5.0 & $4-6$ \\
3. Consultation effectiveness & 4.5 & $4-5$ & 4.8 & $4-5$ \\
4. Referral of consultation to other teachers & 5.8 & $5-6$ & 5.0 & $4-6$ \\
5. Behavior problem warrants this & 5.5 & $5-6$ & 5.6 & $5-6$ \\
$\quad$ consultation model & & & & \\
6. Suitability of consultation & 5.5 & $5-6$ & 5.0 & $4-6$ \\
7. Willingness to use consultation again & 5.8 & $5-6$ & 5.2 & $4-6$ \\
8. No negative side-effect & 5.3 & $5-6$ & 5.2 & $4-6$ \\
9. Appropriateness for variety of children & 5.5 & $5-6$ & 5.0 & $4-6$ \\
10. Consistent with previous consultations & 5.5 & $5-6$ & 4.8 & $4-6$ \\
11. Fairness of consultation & 5.3 & $5-6$ & 5.0 & $4-6$ \\
12. Reasonability of consultation & 5.5 & $5-6$ & 5.0 & $4-6$ \\
13. Pleased with consultation procedures & 5.3 & $5-6$ & 5.0 & $4-6$ \\
14. Appropriateness of consultation & 5.3 & $5-6$ & 5.2 & $4-6$ \\
15. Beneficial for child & 4.8 & $3-6$ & 5.0 & $3-6$ \\
16. Produced quick improvement & 4.3 & $2-6$ & 4.2 & $2-6$ \\
17. Produced lasting improvement & 3.0 & $2-5$ & 4.0 & $2-6$ \\
18. Produced improvement equal to peers & 4.0 & $2-5$ & 4.0 & $2-5$ \\
19. Positive change noticed soon & 4.0 & $3-5$ & 4.2 & $3-5$ \\
20. Maintenance of behavior change & 4.0 & $2-5$ & 2.6 & $1-5$ \\
21. Generalization of behavior change & 2.0 & 2 & 3.0 & $1-5$ \\
22. Social comparability after consultation & 3.8 & $2-5$ & 3.4 & $1-6$ \\
23. Behavior no longer a problem & 2.3 & $2-4$ & 2.4 & $1-4$ \\
24. Other behaviors improved & 4.5 & $2-6$ & 3.8 & $2-6$ \\
Total & 4.7 & & 4.5 & \\
\hline
\end{tabular}

Note: Items are scored on a scale of 1-6, with 1 indicating strong disagreement and 6 indicating strong agreement.

failed to complete all items, mean item scores rather than total scores were computed (i.e., each subject's total score averaged across number of items to which they responded). On a scale of 1 (low) to 4 (high) on Part 1 of the instrument (i.e., general satisfaction with training), mean item scores ranged from 3.5 to 4.0 , with a composite item mean of 3.8. Likewise, individual item scores averaged across all subjects were calculated. These data are presented in Table 4. As indicated in Table 4, the items receiving the highest ratings across subjects were related to effectiveness of training at helping consultants deal more effectively with consultees and clients, and desirability of returning to the program for further training. On a scale of 1 (low) to 5 (high) on Part 2 of the scale (i.e., satisfaction with specific training components), mean item scores ranged from 3.2 to 5.0, with a composite item mean of 4.0. Specific training components receiving the highest ratings were the consultation case with the teacher, role-plays with student teachers, and individual supervision. 
Table 4. Item means and ranges on Training Satisfaction Questionnaire

\begin{tabular}{lcc}
\hline Item & Mean & Range \\
\hline & Part I & \\
1. Quality of Training & 3.8 & $3-4$ \\
2. Appropriateness of training & 3.5 & $3-4$ \\
3. Met training needs & 3.6 & $3-4$ \\
4. Recommend to friend & 3.8 & $3-4$ \\
5. Amount of training & 3.6 & $2-4$ \\
6. Helped deal with consultees/clients & 4.0 & 4 \\
7. Overall satisfaction & 3.8 & $3-4$ \\
8. Return to program & 4.0 & 4 \\
Total: Part I & 3.8 & $\mathbf{2 - 4}$ \\
& & \\
& & \\
9. Individual guide & 3.9 & $3-4$ \\
10. Relationship manual & 3.5 & $3-5$ \\
11. Videotape & 3.5 & $3-5$ \\
12. Role-plays: analogue & 4.0 & $3-5$ \\
13. Role-plays: Student-teachers & 4.8 & $4-5$ \\
14. Consultation case & 5.0 & 5 \\
15. Consultation skills checklist & 3.4 & $2-5$ \\
16. Interpersonal skills checklist & 3.2 & $2-4$ \\
17. Consultation log & 4.5 & $4-5$ \\
18.. Individual supervision & 4.8 & $4-5$ \\
19. Group meetings & 3.6 & $3-4$ \\
Total: Part II & $\mathbf{4 . 0}$ & $\mathbf{2 - 5}$ \\
\hline
\end{tabular}

Note. Part I - Possible range of responses was 1-4, with 1 indicating dissatisfaction and 4 indicating extreme satisfaction. Part II - Possible range of responses was 1-5, with 1 indicating not at all helpful, and 5 indicating extremely helpful.

Consultee's Satisfaction with the Consultant. Experienced and student teachers completed the Consultation Services Questionnaire (CSQ) to determine their satisfaction with the consultant with whom they worked. In general, consultees rated consultants very favorably. Again, because all questionnaires were not completed entirely, means rather than total scores were calculated for the CSQ to obtain global ratings of teachers' satisfaction with consultation (i.e., each subject's total score averaged across number of items to which they responded). All items on the CSQ are rated on a scale of 1 (low) to 5 (high). On Part 1 of the scale (i.e., consultees' perceptions of the consultant), mean total scores ranged from 4.6 to 5.0 for experienced teachers, and from 4.3 to 4.9 for student teachers. Likewise, item means (i.e., individual item scores averaged across all subjects) were computed. These data are presented in Table 5. As depicted in the table, individual item means ranged from 4.0 to 5.0 for both inservice and student teachers. Several items were rated very favorably across both experienced and student teachers, including "easy to work with," "a good listener," and "understood important aspects of problems I brought up." 
Table 5. Item Means on Consultation Services Questionnaire Across Student Teachers and Inservice Teachers

\begin{tabular}{lll}
\hline \multirow{2}{*}{ Item } & $\begin{array}{l}\text { Student } \\
\text { Teachers }\end{array}$ Range & Inservice \\
Teachers Range \\
\hline
\end{tabular}

Part I: Effectiveness

1. Easy to work with

$\begin{array}{rrrr}5.0 & 5 & 5.0 & 5 \\ 4.3 & 4-5 & 4.8 & 4-5 \\ 4.8 & 4-5 & 5.0 & 5 \\ 5.0 & 5 & 5.0 & 5 \\ 4.5 & 4-5 & 5.0 & 5 \\ 4.5 & 4-5 & 4.8 & 4-5 \\ 5.0 & 5 & 4.6 & 4-5 \\ 4.0 & 4 & 4.8 & 4-5 \\ 4.8 & 4-5 & 5.0 & 5 \\ 5.0 & 5 & 4.8 & 4-5 \\ 4.5 & 4-5 & 5.0 & 5 \\ 5.0 & 5 & 5.0 & 5 \\ \mathrm{~N} / \mathrm{A} & \mathrm{N} / \mathrm{A} & 4.3 & 4-5 \\ \mathrm{~N} / \mathrm{A} & \mathrm{N} / \mathrm{A} & 4.0 & 3-5 \\ 4.5 & 4-5 & 4.6 & 4-5 \\ 4.8 & 4-5 & 4.8 & 4-5 \\ 4.5 & 4-5 & 4.8 & 4-5 \\ 4.6 & & 4.6 & \end{array}$

Part II: Benefits

18. Able to see complexities of problem situation

19. Able to see other alternatives

20 . Trying some of my own ideas

21 . Encouraged my own decision-making

22. Helped me work with parents

$4.8 \quad 4-5$

$4.3 \quad 4-5 \quad 4.6 \quad 4-5$

$\begin{array}{llll}4.8 & 4-5 & 4.5 & 4-5\end{array}$

$\begin{array}{llll}5.0 & 5 & 4.6 & 4-5\end{array}$

23. Able to solve similar situations in future

N/A $\quad$ N/A $\quad 4.7 \quad 4-5$

Total: Part II

$\begin{array}{llll}4.8 & 4-5 & 4.2 & 3-5\end{array}$

24. Overall effectiveness of consultant

4.6

4.6

Total

5.0

5

$4.8 \quad 4-5$

4.7

4.5

Note. Items are scored on a scale of 1-5, with 1 indicating strong disagreement and 5 indicating strong agreement.

On Part 2 of the CSQ (i.e., benefits gleaned as a result of being involved in consultation), mean total scores ranged from 4.0 to 5.0 for experienced teachers (with a composite mean of 4.6), and from 4.3 to 5.0 for student teachers (with a composite mean of 4.6). As can be seen in Table 5, the items receiving the highest ratings from experienced teachers were: "able to see complexities of the problem situation in greater depth and breadth" and "helped me work more effectively with parents." For student teachers, the items receiving the highest ratings included: "encouraged me to make my own decisions as to management of problems" and "find myself trying out some of my own ideas." On a final CSQ 
item (perceptions of the overall effectiveness of the consultant), all consul tees responded with ratings of 4 or 5 .

\section{DISCUSSION}

This study extends previous research by Kratochwill and his colleagues (Kratochwill et al., 1989; Kratochwill et al., 1991), and makes several important contributions to the consultation training literature. First, client outcome data are reported for actual school cases. Although previous training programs assessed generalization of consultant behaviors to actual cases, little information is available on client behavior change. Behavioral consultation services in the present study were effective at remediating behavioral and academic difficulties in 4 of 5 target clients.

A second strength of the study is that it assessed both satisfaction with consultation services, and the degree to which consultees found services acceptable within the context of their classroom setting. Previous studies evaluated satisfaction with consultation services, however acceptability is likely a function of other factors as well. Whereas satisfaction ratings typically reflect skills and behaviors of the consultant (as assessed on the CSQ), acceptability of services is related to factors such as time investment, severity of the presenting problem, effectiveness at remediating the target behavior, and impact of the services on other students (Elliott, 1988). In light of the relatively large class sizes and competing demands of general education classroom teachers, acceptability of services is important to investigate. This study was among the first field-based projects which evaluated the degree to which consultation services are acceptable to consultees.

Interestingly, consultee ratings on the BIRS-R indicated that the $\mathrm{BC}$ services they received were very acceptable, regardless of the degree to which they perceived them as effective at remediating clients' presenting problems. This suggests that consultees may perceive a number of benefits from consultation, independent of child behavior change. For example, consultees reported being very satisfied with the effectiveness of individual consultants, and rated them highly on items such as "offered useful information" and "understood important aspects of problems I brought up" (as reported on the CSQ). Furthermore, consultees rated consultants very high on the item "helped me work more effectively with parents," although only one consultation case actually involved parents. It is possible that consultees in this study learned effective interviewing and problem-solving skills from consultants that may generalize to other students in their classrooms or to their interactions with parents. These are important potential side effects of consultation that should receive empirical attention.

Previous $\mathrm{BC}$ training projects typically limited their consultation focus to include only teacher consultees. However, the need to work with parents, and to involve parents in educational problem-solving, is receiving increased attention (Christenson \& Conoley, in press; Sheridan \& Kratochwill, 1992). Unfortunately, the most efficacious way to work with parents is unclear, and few 
school personnel receive direct training in interfacing with families. One consultant in the present study provided consultation services to parents and teachers together via a "conjoint behavioral consultation" approach (Sheridan \& Kratochwill, 1992; Sheridan et al., 1990). Although data are limited for this case, it appears that general $\mathrm{BC}$ training provided the consultant with the necessary skills to work effectively with parents and teachers together. Future research should investigate the differential effectiveness of various models to train school psychologists to engage parents and teachers in cooperative consultative problem-solving.

Follow-up interviews with the consultant trainees provided further documentation of the efficacy of the training program. Specifically, two individuals who completed the training (now employed as school psychologists) were interviewed approximately one year following completion of the project. Both reported providing $\mathrm{BC}$ services regularly in their school practice. Furthermore, both stated that skills learned in training generalized into their actual practice, and enhanced their general interactions with teachers. It is possible that various problem-solving strategies, verbal techniques, and interpersonal skills developed in the context of consultation training assisted their professional practices and relationships, although this has not been determined empirically.

Along with the various benefits of the training program, some difficulties were reported by consultants. Specifically, consultants stated that the schoolbased interviews were very time consuming and required several meetings between consultants and consultees. However, while this was reported as a limitation by consultants, none of the consultees indicated similar concerns. Thus, it appears that time issues (often reported as a significant barrier to implementing consultation in applied settings) may be a concern to service providers as well as consumers. Obtaining case information prior to the initiation of consultation services may be helpful to consultants to streamline the problem-solving process. For example, a consultation referral form can be used to elicit information regarding consultee concerns and suggest directions for follow-up by the consultant. Record reviews, direct observations, and analysis of permanent products are additional sources of assessment data that can provide consultants with important information and promote reliable and accurate problem identification outside of the formal consultation interviews.

Although this study provides several advances in the consultation training literature, it is not without its weaknesses. First, while the multiple baseline design provides a viable and useful methodology in applied research, there were nevertheless only five consultant subjects utilized in this research. Furthermore, child clients were treated in a series of single case studies with little follow-up data. Ratings on the BIRS-R also reflect limited generalization of consultation outcome beyond the immediate child subjects and treatment settings. Thus, caution must be exercised when generalizing both training and treatment results beyond the present investigation. 
A second issue limiting the generalization of results concerns the nature of consultant training used in the study. Specifically, a research grant was obtained by the author, and all training was conducted independent of formal consultation courses. However, in most settings consultation training will occur in the context of formal coursework which may not be conducive to applied experiences. At this time, it is unclear whether these extensive training procedures can be integrated practically and meaningfully into consultation course curricula.

Third, limitations can be identified in relation to some of the dependent measures. The primary outcome measures were direct behavioral assessments (i.e., consultant skills and child behaviors). Although systematic objective data are available for consultant verbal behaviors, behavioral data for child subjects are limited. Furthermore, no interrater reliability data were collected. The collection of reliable and repeated behavioral data by consultees in naturalistic settings poses several challenges. Given the critical importance of this type of data in consultation research, practical and valid procedures must be identified. This is particularly important for scientist-practitioners striving to increase accountability of their services.

Another weakness regarding dependent measures concerns the nature of consumer satisfaction and acceptability data. Specifically, these variables were measured via subject self-reports, and several of the rating scales were developed or adapted for the project. Given these data it is impossible to rule out the existence of a halo effect in consultee responses. Furthermore, psychometric support for the TSQ and CSQ is unavailable. More valid and objective methods of assessing these domains may be documentation of continued use of the $\mathrm{BC}$ model by consultants or request for services by consultees. Two consultant subjects were interviewed informally in the present study; however, more systematic and objective attention should be given to these important dimensions of consultation services in future research.

Fourth, problems with plan development and treatment integrity are apparent. Specifically, there is no information on how interventions were selected. The extent to which consultants and consultees conducted careful functional analyses of client problems clearly impacts the outcome of interventions. Furthermore, no data are available on the integrity with which consultees carried out chosen interventions. Because these data are not readily available, it is difficult to determine whether case outcomes were a function of the consultation process, intervention selection, treatment implementation issues, or some combination of these.

One case in the present study (Subject 5) met with equivocal results. Interestingly, this consultant and consultee had more meetings than other consultation dyads (i.e., they met for 10 interviews, for approximately one to one and one-half hours per meeting). Several of these interviews were informal meetings and deviated significantly from the standard $\mathrm{BC}$ procedures. In this case, the consultant failed to adhere to the standardized BC protocol, and her efforts to obtain coop- 
eration from the teacher in data collection and intervention follow-through were unsuccessful. Given the critical importance of integrity in the problem-solving process (e.g., procedural skills, data collection, and treatment implementation), personal variables and their impact on consultation outcome should be investigated more carefully in future research. This may be accomplished through detailed verbal analyses of consultation transcripts using relational communication or content coding systems (Witt, 1990). It is particularly important to analyze resistance to the entire problem-solving process, in relation to both consultee and consultant behaviors.

Finally, it must be noted that this project dealt solely and specifically with the training of behavioral consultants. Modification of materials and field-testing are necessary prior to its expansion to other models. Given the promise of competency-based approaches to training, this may provide fertile ground for future consultation research.

\section{References}

American Association of School Administrators (AASA). (1988). Challenges for school leaders. Arlington, VA: Author. Alpert, J. L., \& Yammer, M. D. (1983). Research in school consultation: A content analysis of selected journals. Professional Psychology: Research and Practice, 14, 604-612.

Barlow, D. H., Hayes, S. C , \& Nelson, R. O. (1984). The scientist practitioner: Research and accountability in clinical and educational settings. New York: Pergamon Press.

Bergan, J. R., \& Kratochwill, T. R. (1990). Behavioral consultation and therapy. New York: Plenum. Christenson, S. L., \& Conoley, J. C. (in press). (Eds.) Home-school collaboration: Building a fundamental educational resource. Washington, DC: National Association of School Psychologists.

Christenson, S., Ysseldyke, J. E., \& Algozzine, B. (1982). Institutional constraints and external pressures influencing referral decisions. Psychology in the Schools, 19, 341-345.

Curtis, M. J., \& Meyers, J. (1988). Consultation: A foundation for alternative services in the schools. In J. L. Graden, J. E. Zins, \& M. J. Curtis (Eds.), Alternative educational delivery systems: Enhancing options for all students (pp. 35-48). Washington, DC: National Association of School Psychologists.

Elliott, S. N. (1988). Acceptability of behavioral treatments: Review of variables that influence treatment selection. Professional Psychology: Research and Practice, 19, 68-80.

Elliott, S. N., \& Von Brock Treuting, M. (1991). The Behavior Intervention Rating Scale: Development and validation of a pretreatment acceptability and effectiveness measure. Journal of School Psychology, 29, 43-52.

Fuchs, D., Fuchs, L. S., \& Bahr, M. W. (1990). Mainstream Assistance Teams: Scientific basis for the art of consultation. Exceptional Children, 57, 128-139.

Gelfand, D. M., \& Hartmann, D. P. (1984). Child behavior analysis and therapy (2nd ed.). New York: Pergamon.

Gresham, F. M., \& Elliott, S. N. (1990). Social Skills Rating System. Circle Pines, MN: AGS. Gresham, F. M., \& Kendall, G. K. (1987). School consultation research: Methodological critique and future research directions. School Psychology Review, 16, 306-316. 
Idol-Maestas, L., \& Ritter, S. (1985). A follow-up study of resource/consulting teachers: Factors that facilitate and inhibit teacher consultation. Teacher Education and Special Education, 8 (3), 121-131.

Knitzer, J. (1982). Mental health services to children and adolescents: A national view of public policies. American Psychologist, 39, 905-911.

Kratochwill, T. R., \& Bergan, J. R. (1978). Training school psychologists: Some perspectives on a competency-based behavioral consultation model. Professional Psychology, 9, 71-82.

Kratochwill, T. R., \& Bergan, J. R. (1990). Behavioral consultation in applied settings: An individual guide. New York: Plenum.

Kratochwill, T. R., Elliott, S. N., \& Rotto, P. J. (1990). Best practices in behavioral consultation. In A. Thomas \& J. Grimes (Eds.), Best practices in school psychology—II (pp. 147169). Washington, DC: NASP.

Kratochwill, T. R., Sheridan, S. M., Rotto, P., \& Salmon, D. (1991). Preparation of school psychologists to serve as consultants for teachers of emotionally disturbed children. School Psychology Review, 20, 530-549.

Kratochwill, T. R., Sheridan, S. M., Rotto, P., \& Salmon, D. (1992). Preparation of school psychologists in consultation service delivery: Practical, theoretical, and research considerations. Chapter to appear in T. R. Kratochwill, S. N. Elliott, \& M. Gettinger (Eds.), Advances in school psychology (Vol. VIII, pp. 115-152). Hillsdale, NJ: Erlbaum Associates.

Kratochwill, T. R., Van Someren, K. R., \& Sheridan, S. M. (1989). Training behavioral consultants: A competency-based model to teach interview skills. Professional School Psychology, 4, 41-58.

Lloyd, J. W., Singh, N. N., \& Repp, A. C. (1991). The Regular Education Initiative: Alternative perspectives on concepts, issues, and models. Sycamore, IL: Sycamore Publishers.

Mannino, F. V., \& Shore, M. F. (1975). The effects of consultation: A review of empirical studies. American Journal of Community Psychology, 17, 275-282.

Medway, F. J. (1979). How effective is school consultation: A review of recent research. Journal of School Psychology, 17, 275-282.

Medway, F. J., \& Updyke, J. F. (1985). Meta-analysis of consultation outcome studies. American Journal of Community Psychology, 13, 489-505.

National Association of School Psychologists/National Coalition of Advocates for Students (1985). Advocacy for appropriate educational services for all children. Washington DC: Author.

Phillips, V, \& McCullough, L. (1990). Consultation-based programming: Instituting the collaborative ethic. Exceptional Children, 56, 291-304.

Pray, B., Kramer, J. J., \& Lindskog, R. (1986). Assessment and treatment of tic behavior: A review and case study. School Psychology Review, 15, 418-429.

Rotto, P. J., \& Sheridan, S. M. (1987). Behavioral observation training manual. Unpublished manual, Wisconsin Center for Educational Research, University of Wisconsin-Madison.

Rotto, P. J., Sheridan, S. M., \& Salmon, D. (1987). Interpersonal considerations in the consultative relationship: A manual. Unpublished manual, University of Wisconsin-Madison, Wisconsin Center for Education Research, Madison, Wisconsin.

Saxe, L., Cross, T, \& Silverman, N. (1988). Children's mental health: The gap between what we know and what we do. American Psychologist, 43, 800-807.

Sheridan, S. M., \& Elliott, S. N. (1991). Behavioral consultation as a process for linking the assessment and treatment of social skills. Journal of Educational and Psychological Consultation, 2, 151-173. 
Sheridan, S. M., \& Kratochwill, T. R. (1992). Behavioral parent-teacher consultation: Conceptual and research considerations. Journal of School Psychology, 30, 117-139.

Sheridan, S. M., \& Kratochwill, T. R, (1991). Behavioral consultation in educational settings. In J. W. Lloyd, N. N. Singh, \& A. C. Repp (Eds.), The Regular Education Initiative: Alternative perspectives on concepts, issues, and models (pp. 193-210). Sycamore, IL: Sycamore Publishing Co.

Sheridan, S. M., Kratochwill, T. R., \& Elliott, S. N. (1990). Behavioral consultation with parents and teachers: Delivering treatment for socially withdrawn children at home and school. School Psychology Review, 19, 33-52.

Sheridan, S. M., Salmon, D., Kratochwill, T. R., \& Rotto, P. J. (1992). Conceptual and practical considerations for behavioral consultation training. Journal of Educational and Psychological Consultation, 3, 193-218.

Stainback, W., \& Stainback, S. (1991). Rationale for integration and restructuring: A synopsis. In J. W. Lloyd, N. N. Singh, \& A. C. Repp (Eds.), The Regular Education Initiative: Alternative perspectives on concepts, issues, and models (pp. 241-255). Sycamore, IL: Sycamore Publishers.

Von Brock, M. B., \& Elliott, S. N. (1987). Influence of treatment effectiveness information on the acceptability of classroom interventions. Journal of School Psychology, 25, 131-144.

West, J. F., \& Idol, L. (1987). School consultation (Part I): An interdisciplinary perspective on theory, models, and research. Journal of Learning Disabilities, 20, 388-408.

Wilson, F. R., Curtis, M. J., \& Zins, J. E. (August, 1987). Consultant self-managed behavior change during consultation training. Paper presented at the annual meeting of the American Psychological Association, New York.

Witt, J. C. (1990). Face-to-face verbal interaction in school-based consultation: A review of the literature. School Psychology Quarterly, 5, 199-210.

Ysseldyke, J. E., Algozzine, B., Richey, L., \& Graden, J. L. (1982). Declaring students eligible for learning disability services: Why bother with the data? Learning Disability Quarterly, 5, 37-44.

Zins, J. E. (1981). Using data-based evaluation in developing school consultation services. In M. J. Curtis \& J. E. Zins (Eds.), The theory and practice of school consultation (pp. 261268). Springfield, IL: Charles C. Thomas.

Zins, J. E. (1984). A scientific problem-solving approach to developing accountability procedures for school psychologists. Professional Psychology: Research and Practice, 15, $56-66$.

Zins, J. E., Curtis, M. J., Graden, J. L., \& Ponti, C. R. (1988). Helping students succeed in the regular classroom. San Francisco: Jossey-Bass. 